Article

\title{
Reconstruction of Earth Extreme Topography from UAV Structure from Motion Photogrammetry
}

\author{
Francisco Agüera-Vega ${ }^{1,}$ *, Fernando Carvajal-Ramírez ${ }^{1}$, Patricio J. Martínez-Carricondo ${ }^{1}$ and \\ Julián Sánchez-Hermosilla López ${ }^{1}$ \\ 1 Department of Engineering, University of Almeria, Campus de Excelencia Internacional Agroalimentario, \\ ceiA3, Carretera de Sacramento s/n, La Cañada de San Urbano, Almeria, C.P. 04120, Spain. \\ * Correspondence: faguera@ual.es; Tel.: +34-950-015-977
}

\begin{abstract}
UAV photogrammetry development during the last decade has allowed to catch information at a very high spatial and temporal resolution from terrains with very difficult or impossible human access. This paper deals with the application of these techniques to study and produce information of very extreme topography which is useful to plan works on this terrain or monitoring it over the time to study its evolution. The methodology stars with the execution of UAV flights on the cut slope studied, one with the cam horizontally oriented and other at $45^{\circ}$ respect that orientation. Ground control points (GCPs) and check points (CPs) were measured for georeference and accuracy measurement purposes. Orthophoto was obtained projecting on a fitted plane to a studied surface. Moreover, since a digital surface model (DSM) is not able to represent faithfully that extreme morphology, information to project works or monitoring it has been derived from the point cloud generated during the photogrammetric process. An informatics program was developed to generate contour lines and cross sections derived from the point cloud, which was able to represent all terrain geometric characteristics, like several $Z$ coordinates for a given planimetric $(X, Y)$ point. Results yield a root mean square error (RMSE) in $X, Y$ and $Z$ directions of $0.053 \mathrm{~m}, 0.070 \mathrm{~m}$ and $0.061 \mathrm{~m}$ respectively. Furthermore, comparison between contour lines and cross sections generated from point cloud with the developed program on one hand and those generated from DSM on other hand, shown that the former are capable of representing terrain geometric characteristics that the latter cannot. The methodology proposed in this work has been shown as an adequate alternative to generate manageable information, as orthophoto, contour lines and cross sections, useful for the elaboration, for example, of projects for repairing or maintenance works of cut slopes with extreme topography.
\end{abstract}

Keywords: Unmanned Aerial Vehicle (UAV); UAV-photogrammetry; Structure From Motion (SfM); cut slope; extreme topography; landslide

\section{Introduction}

During the past decade there have been a quick technological development related to digital elevation modelling. For the most of geomorphic applications, topographic surveys have been mainly conducted using robotic total stations [1], or differential global navigation satellite system (GNSS) [2,3]). Nowadays, news technologies, such as terrestrial laser scanning (TLS) [4], aerial laser scanning (ALS) [5], softcopy photogrammetry [6,7], or aerial light detection and ranging (LiDAR) [8], have improved the accuracy of digital elevation models (DEMs) but they are often time-consuming and costly.

Landforms with complex topography can make these methodologies cannot be used and even prove dangerous for operators. Furthermore, in the most dynamic environments is necessary to have high temporal frequency at a very high spatial resolution images and DEMs for studying their evolution. This is especially necessary when the landform evolution may cause both human and economic disaster, as is the case of infrastructure built on these kinds of landforms. 
The use of consumer grade cameras mounted on Unmanned Aerial Vehicles (UAVs) to recover this information is being investigated from several years ago to overcome the limitations of actual techniques $[9,10]$. UAVs present distinct advantages over conventional piloted aircrafts and satellites, especially their low cost, operational flexibility and better spatial and temporal resolution $[11,12,13]$. UAVs require less time than others techniques in data acquisition and, therefore, reduce the cost [14]. Moreover, UAV imagery provides results at a resolution and accuracy that cannot currently be met by satellite derived products [15] and are very useful in places where the use of others techniques are dangerous. The great development of these systems in recent years and the miniaturization of sensors have increased the civil applications of UAVs [16]. A detailed description of this evolution and about the state of the art can be found in [17], and a review of the applications of UAV in civil engineering in general and in 3D mapping application in particular, can be found in [18] and [19] respectively.

The integration of computer vision and image analysis have derived in a technique called Structure-from-Motion $[19,20]$, which solves automatically the geometry of the scene, the camera positions and orientation, without the need to specify a priori a network of targets which have known 3-D positions [21,22,23]. SfM incorporates multi-view stereopsis (MSV) techniques [24], which derives 3D structure from overlapping photography acquired from multiples angles. Lowe [25,26] and Snavely et al. [21] applied Scale Invariant Feature Transform (SIFT) operator for key-point detection for generating 3D point clouds from photographs. There are works concluding that this operator is one of the most robust to large image variations [27,28]. A more detailed description of SfM can be found in [3 ] and [22].

SfM with MVS has passed the lower precision showed by traditional photogrammetric DEMs against airborne LiDAR. There are works which yielded terrain models with centimetre precision and point cloud resolutions that fall between LiDAR and TLS [29].

Recent studies have been carried out using UAV imagery and SfM techniques with geomorphologic and terrain mapping purposes: Harwin and Lucieer [12] report accuracies of 0.025-0.040 $\mathrm{m}$ in the point cloud of a natural landform generated from UAV imagery and SfM techniques. Lucieer et al. [30] generated high resolution DSM of Antartic moss beds from UAV imagery obtaining an overall root mean square error (RMSE) of $0.420 \mathrm{~m}$. Mancini et al. [31] studied the creation and validation of point clouds and DSM, generated from images taken by a DSLR camera mounted on a rotatory-wing UAV, of a beach dune system. The UAV-based approach was demonstrated to be straightforward and accuracy of the vertical dataset was comparable with results obtained by TLS technology. In [32], Lucieer et al. used UAV imagery for mapping landslide displacements. DEMs and orthoimages were exported at $1 \mathrm{~cm}$ resolution resulting RMSEXY of 0.070 $\mathrm{m}$ and RMSEZ of $0.062 \mathrm{~m}$. In [33], a rotary wing UAV was used to recover images for topographic surveys and they concluded that the DSM produced from the UAV imagery was in good agreement with the total station survey points. Eltner et al. [34] measured surface changes of short term erosion events using images taken from a rotary-wing UAV and these data were compared to a DSM produced with TLS data, pointing out that DSMs have an accuracy of less than one centimetre.

The work of Clapuyt et al. [10] compared different SfM-derived topography datasets resulting from identical replications and observed in all cases precisions of measurements in the order of centimetres, which demonstrated the reproducibility of UAV-based earth topography reconstructions based on SfM algorithms. In [35] the influence of several factors (flight altitude, number of ground control points (GCPs), and terrain morphology) on DSM and orthoimage obtained with UAV photogrammetry, was explored. With a flight altitude of $50 \mathrm{~m}$ and $10 \mathrm{GCP}$, they yield accuracies of $0.053 \mathrm{~m}$ in planimetry, and $0.049 \mathrm{~m}$ in altimetry, but all morphologies studied allowed to access to any point to take coordinates measurement or other related work. Fernandez et al. [36] made an analysis of landslide evolution studying the terrain displacements along several years. The terrain morphology and the objective of this work made to adapt the usual UAV photogrammetry methodology, using GCPs which were static along the time of the study, in complex terrain morphology. In [37], very complex terrain morphology was studied, even with areas where it could not be accessed. They only can use GCP located around the study area and 
compared accuracies of photogrammetric projects differing in the image orientation: orthogonal images oriented to the terrain on the one hand, and classical vertical images orientation, on the other hand. They concluded that the first methodology is more adequate for this kind of morphology.

Therefore, in the light of the above, there has been a great development of UAV photogrammetry in recent years and is increasingly used in situations where classical photogrammetry is less efficient or simply not applicable. All this makes necessary to continue to deepen the development of specific methodologies to obtain accurate results using UAV photogrammetry in extreme situations, where classical photogrammetry has not even been able to arrive.

This paper provides a methodology to obtain photogrammetrically derived topographic information from UAV imagery for earth extreme and dynamic topography, where traditional techniques are dangerous or impossible to apply. The goals were to quantify the accuracy of the generated point cloud, and provide useful cartographic material for engineers, geologists and other technicians, of the terrain with extreme morphology.

\section{Study area}

The study area is a cut slope located at the N-340 road, in the province of Almería, southeast Spain, between Almería city and Aguadulce (Figure 1). This road was the longest in Spain (1248 km) and runs along the Mediterranean Sea coast from Cádiz to Barcelona. Nowadays there is a new parallel dual carriageway called A7 but N-340 has a heavy traffic, especially in sections that connect nearby cities. Like many coastal roads, N-340 has numerous cut slopes built in unstable rocky areas and there is a risk of landslides.
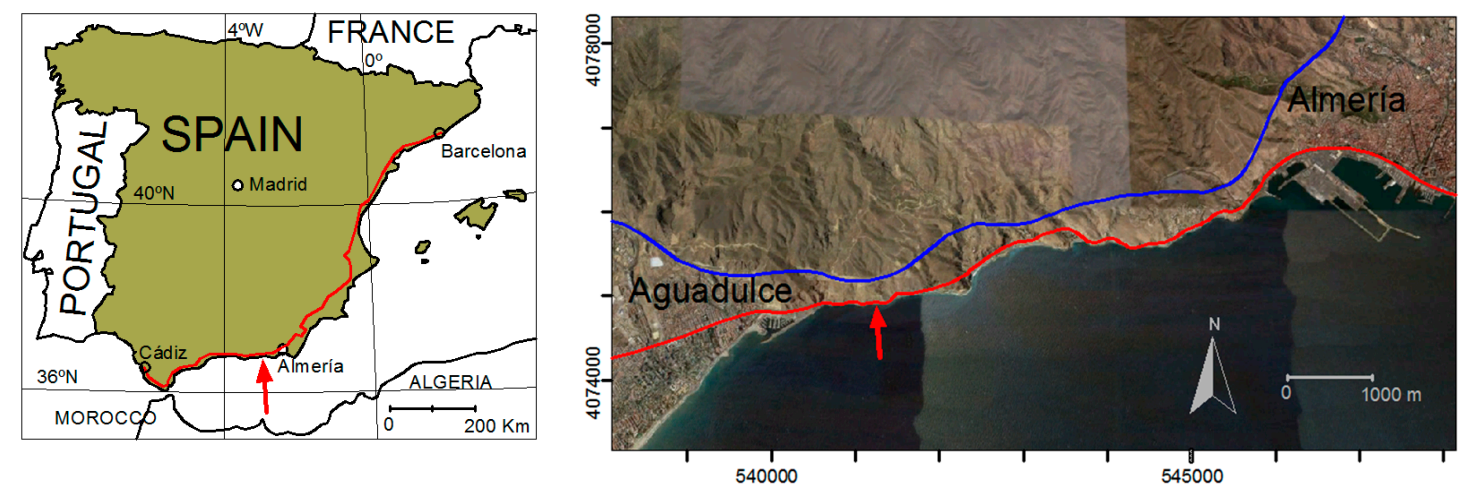

Figure 1. Geographical location of the study area. The red arrow indicates the location of the study area. Red line represents the N-340 road and the blue line represents the A7 dual carriageway.

The studied cut slope has $130 \mathrm{~m}$ long and the highest elevation difference between the road and the top of the cut slope is $70 \mathrm{~m}$ (Figure 2a). It has slopes almost vertical, even negative slopes, ie, part of the cut slope is suspended over the road. Furthermore, it suffered a landslide caused by torrential rains (Figure $2 b$ ) and it was necessary to have cartographic material to study its stability status and repair it. Traditional technics (Global Navigation Satellite Systems: GNSSs, terrestrial laser station, total station, ...) were not possible to use here because the terrain morphology. So, the best option, and perhaps the only, was to carry out a UAV-photogrammetric project. 

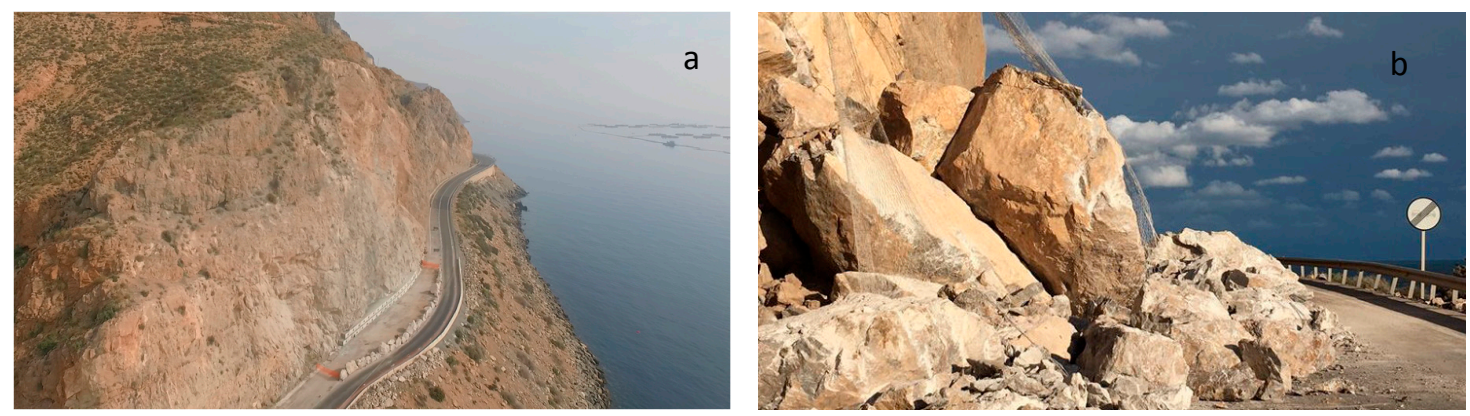

Figure 2. Studied cut slope (a) and landslide caused by torrential rains (b).

\section{Materials and methods}

The methodology applied was based on digital UAV-photogrammetry techniques, experimented by the authors in previous works, with adaptations to the particular characteristics of the studied morphology.

\subsection{Image Collection}

A rotatory-wing UAV with eight rotors (OktoKopter) and MikroKopter (Moormerland, Germany) electronic boards was used to take the images. The OktoKopter has a payload of $2.5 \mathrm{~kg}$ and a motion-compensated gimbal for the sensor was mounted on it. The sensor was a Nikon 3100 reflex camera with a lens with $16 \mathrm{~mm}$ fixed focal length. This camera has a complementary metal-oxide semiconductor (CMOS) sensor of 14.8 effective megapixels with a size of $355.7 \mathrm{~mm} 2$ $(23.1 \times 15.4 \mathrm{~mm})$. Figure 3 shows the entire system.
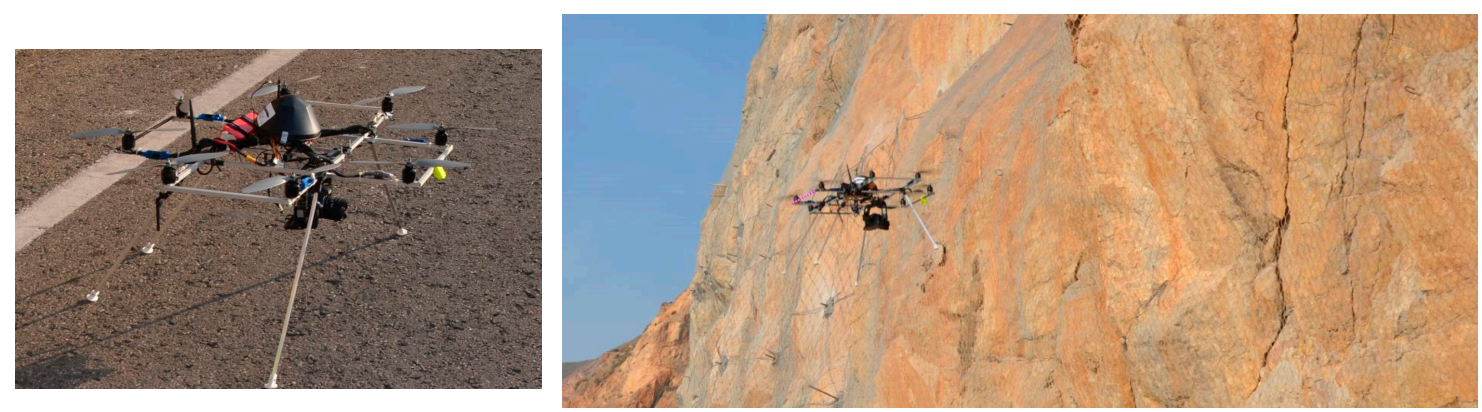

Figure 3. UAV equipment used in this work.

The flight plan was programmed and loaded to the UAV using the MikroKopter-Tool [38] software. In order to photography the whole complicated cut slope surface, two flights were executed varying the photography axis: one with horizontal orientation and one with the axis tilted $45^{\circ}$ downwards. During all these flights, the UAV remained in a vertical plane at a distance of approximately $50 \mathrm{~m}$ to the studied surface. As the image resolution was adjusted to $4240 \times 2832$ pixels, the ground sample distance (GSD) was $1.86 \mathrm{~cm}$. The flight altitude varied from the road level to $100 \mathrm{~m}$, the overlap between pictures was $90 \%$.

Furthermore, 3D coordinates of several points scattered on the studied surface were measured with a total station without reflector. Altitude of these points could not be greater than around $35 \mathrm{~m}$ from the road level because the angle of the station telescope was very high and was not possible to look across the telescope. Of these points, those not located on the cut slope were measured using GNSSs. Two of these three points were used for orientating the measured points with the total station to a local coordinate system. The GNSSs measurements were made working with differential corrections in real-time kinematic (RTK) mode, with the base station on a geodesic pillar located closer than $1 \mathrm{~km}$ from the studied site. Both rover and base GNSS receivers were Trimble R6. For the RTK measurements, these dual-frequency geodetic instruments, which track the Global Position 
System (GPS) and Global Navigation Satellite System (GLONASS) signals simultaneously, have manufacturer's stated accuracy specifications of $\pm 8 \mathrm{~mm}+1$ ppm RMS horizontal and $\pm 15 \mathrm{~mm}+1$ ppm RMS vertical. Therefore, the maximum horizontal and vertical RMSs were \pm 9 and $\pm 16 \mathrm{~mm}$, respectively. The total station without reflector was a Stonex, STS22R model. This instrument has a measurement range, without reflector or white target, of approximately $100 \mathrm{~m}$, and an accuracy of $5 \mathrm{~mm}+2 \mathrm{ppm}$ in reflector-less fine mode.

\subsection{Image Processing}

The images were processed using the software Pix4Dmapper Pro, version 3.1 [39]. This package incorporates the SfM procedure described in [40] and has a three-step workflow. The first step of the images processing is to compute keypoints on them, which will be used to find matches between the images, and from these, to run an automatic aerial triangulation and bundle block adjustment. Images taken in this work were not geotagged. The internal calibration parameters, the relative camera position and orientation corresponding to each picture and the 3D relative coordinates of a sparse point cloud of the terrain are the results of this first step. To refer all these results to a local coordinate system the coordinates of measured GCPs and CPs are added to the project and the point are marked on the pictures where they appear. In this work, the coordinates of 18 points located on the cut slope were measured with the total station. It was very difficult to locate points on the cut slope which could be identified in the photos to georreference the point cloud. Vertex of characteristics shapes or metallic pieces of older works on the cut slope were used. Furthermore coordinates of 8 points scattered on the road and marked with targets of A4 format size (210x297 $\mathrm{mm}$ ) were measured with total station and with GNSSs to refer the local coordinates system of the total station to the local system. Figure 4 shows the target used on the road (right) and one of the metallic piece used as target in the cut slope (left).
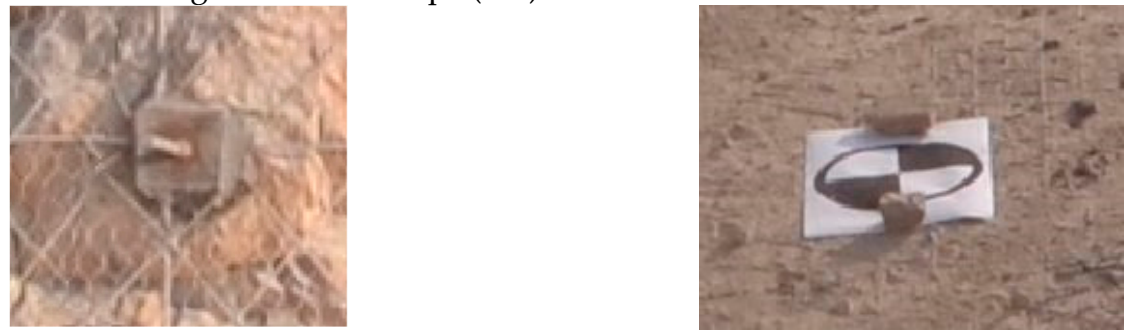

Figure 4. Detail of the target used for the measurements of GCPs and CPs located on the cut slope (left) and that used for those located on the road (right).

The second step achieves a densification of the point cloud and a more detailed 3D model than that of step 1 is obtained. Finally, in the third step, a grid DSM can be generated at a specific grid size and the orthophoto is exported at a pre-selected resolution. The bundle adjustment can be carried out using only three GCPs, but it is advisable to use more than three to obtain optimal accuracy $[35,41,42,43]$.

As the study surface is almost vertical, the orthophoto obtained when projecting on a horizontal plane does not offer valuable information, even confusing information, because there are zones where for a given $X$ and $Y$ coordinates, two or more $Z$ coordinates can be present. To avoid this circumstance, a plane was adjusted to the cut slope surface and it was used to project for building the orthophoto. This plane was determined by fitting to the terrain point cloud obtained in the second step of the image processing, previously described. For this task, only the points centered on the interest area were taking into account. The resulting orthophoto will provide valuable information for the study of the cut slope surface: location and description of cracks, location of rocks with danger of falling into the road, take measurements or get information to plan works on the cut slope. 


\subsection{Point cloud management}

Coordinates of dense point cloud obtained from photogrammetric process were referred to as UTM Zone 30N (European Terrestrial Reference System 1989, ETRS89) and the elevation as the mean sea level using the EGM08 geoid model. A DSM obtained from this point cloud would lose a lot of information due to the surface geometric characteristic mentioned above: regardless the reference plane taken into account, for a given $X$ and $Y$ coordinates, there will be areas where two or more $\mathrm{Z}$ coordinates are found, and it is not compatible with a DSM. Then, to get the most out of the information provided by the point cloud, an informatics program was developed to obtain, from the raw point cloud, contour lines on one hand and cross sections produced by vertical and perpendicular planes to the fitted plane on the other hand, at any point of the work area. This kind of terrain representation shows a very realistic vision of the surface shape and it is useful to plan and execute works on the terrain under study. The program had two main parts. In the first part, contour lines and vertical section are extracted from the point cloud. For this task, the program determines maximum and minimum $\mathrm{X}, \mathrm{Y}$ and $\mathrm{Z}$ coordinates presented in the point cloud and the user can select the extreme coordinate to fix the box which will be studied. A dialog box (Figure 5a) shows the extreme coordinates of raw point cloud (blue color in the figure $5 b$ ) and it allows to fix the limits of the box which will be studied (green color in the figure $5 \mathrm{~b}$ ). Names of the file containing raw cloud data and processed data should be indicated in the bottom of the dialog box. The output file is structured by three columns, containing coordinates $X, Y$, and $Z$, respectively, of those points inside the box to be studied (green box in $5 b$ ). When this file is created, the second step starts showing a dialog box (Figure 5c) for generating horizontal and vertical cut slope sections (blue and red sections, respectively, in figure 5d). In this figure, $\omega$ is the fitted plane, $\varphi_{i}$ and $\varphi_{i+1}$ the relative position of two consecutive horizontal planes which generate two consecutive contour lines, $\pi_{i}$ and $\pi_{i+1}$ are two consecutive vertical planes which generate two consecutive cross sections. A and B are the points defining the intersection straight line between the horizontal plane with the minimum coordinate $Z$ considered, and $\omega$. So, $Z$ range will be $Z$ max-Zmin and $X Y$ range will come from the distance between $A$ and $B\left(d_{A B}\right)$. Number of horizontal sections will be $(Z \max -Z m i n) / \Delta v$ and number of vertical sections will be $d_{A B} / \Delta h$. In this dialog box, "Width section" mains the maximum distance from one point of the cloud to the vertical cut plane $\left(\pi_{1}, \pi_{2}, \ldots\right)$ or horizontal cut plane $\left(\varphi_{1}, \varphi_{2}, \ldots\right)$, to be considered included in the section. This was taken into account to ensure a minimum number for a good definition of the section. In the top of the "Section generation" dialog box, the coordinates defining the cloud box to be studied, $\mathrm{Z}$ variation range and distance between $\mathrm{A}$ and $\mathrm{B}$ points (figure $5 \mathrm{c})$ are showed. Then, distances in meters between consecutive vertical $(\Delta \mathrm{v})$ and horizontal $(\Delta \mathrm{h})$ section are fixed (in the Figure $5 \mathrm{c}$, both of them are fixed to $1 \mathrm{~m}$ ). Furthermore, the width vertical and horizontal sections are fixed to $0.01 \mathrm{~m}$ but this value can be changed. This is a critical adjustment because the accuracy of sections representation depends on this value. If it is too low, few points will be extracted and the section will be poorly defined. On the other hand, if this value is too high, a lot of points will be extracted and the section will be confusedly defined. So, to get an optimal value, an informatics program was developed to compare results taking into account several values of cutting plane width.

For a given $Z$, contour lines file are structured by two columns containing coordinates $\mathrm{X}, \mathrm{Y}$ coordinates. Files containing cross sections are structured by two columns too, one for de distance measured on the intersection of $\pi_{\mathrm{i}}$ with the horizontal plane, and the other column for the coordinate Z. One file is created for each section. 

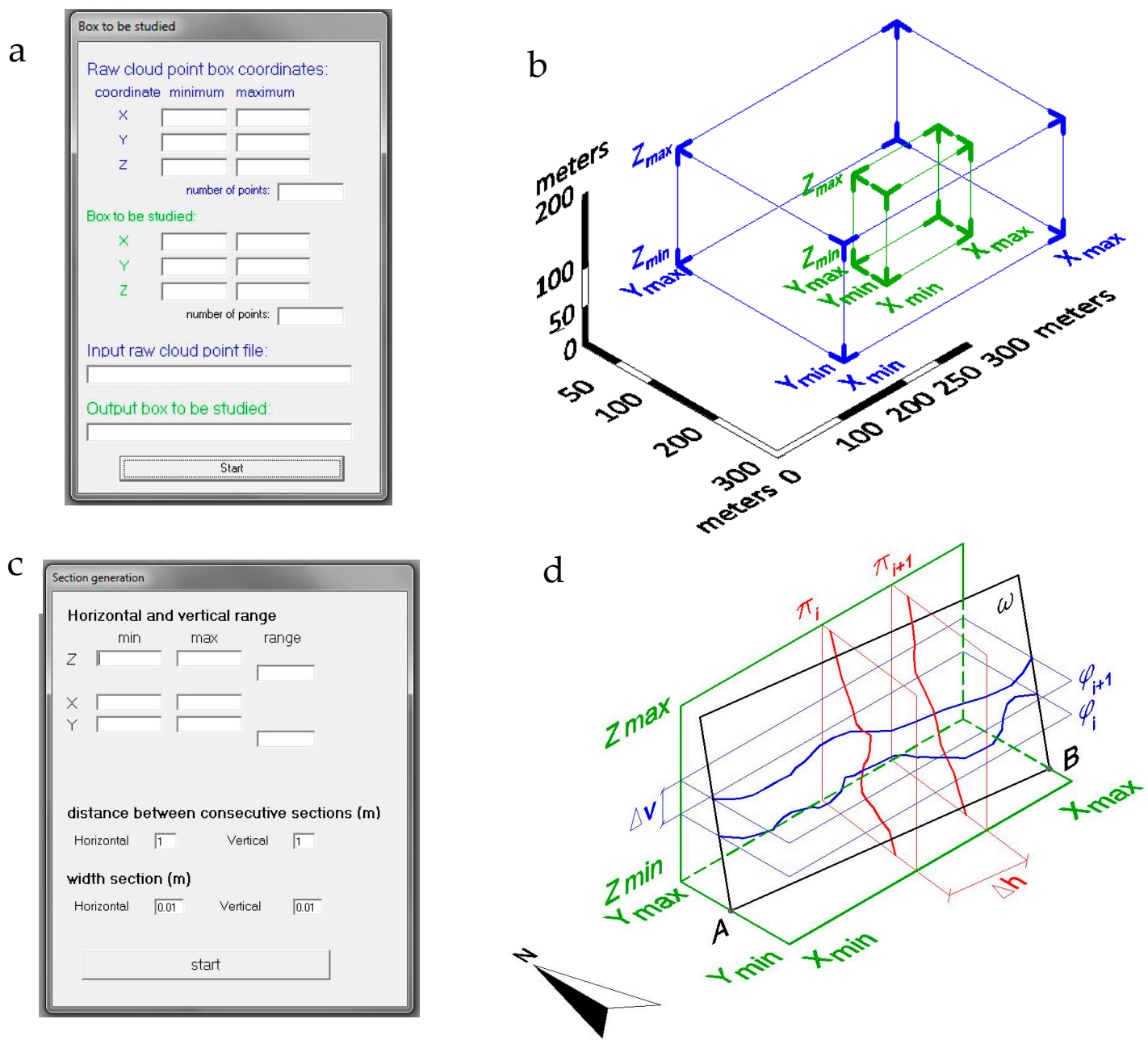

Figure 5. Program developed to obtain horizontal and vertical sections files: (a) dialog box for delimiting the work area; (b) graphical representation: blue prism indicates the whole space covered by the pictures and green prism indicates the selected area; (c) dialog box for generating level and cross; (d) graphical representation of the sections generation.

The second part of the developed program allows display the generated sections. Its interface shows three graphical windows (figure 6): the main one for the orthophoto, projected on the fitted plane, other for the contour line, above the orthophoto windows, and the third for the cross section. When a click is done on the cut slope image, a cross appear on that, representing the intersection of the horizontal (red) and vertical (blue) planes with the terrain, and immediately the contour line and the cross section are drawn in its respective window. Extreme coordinates of each window, contour line elevation are showed. Furthermore, when the cursor is on the orthophoto, coordinates are showed in the bottom.

\subsection{Accuracy assessment}

For every $\mathrm{CP}$, the accuracy assessment in Easting $(\mathrm{X})$, Northing $(\mathrm{Y})$ and height $(\mathrm{Z})$, was performed by comparing the CPs measured coordinates with the interpolated coordinates from the four nearest points of the dense cloud generated in the photogrammetric process, resulting in RMSEX, RMSEY and RMSEZ accuracy measures, respectively:

$$
\operatorname{RMSE}_{\mathrm{X}}=\sqrt{\frac{\sum_{\mathrm{i}=1}^{\mathrm{n}}\left[\left(\mathrm{X}_{\mathrm{si}}-\mathrm{X}_{\mathrm{ci}}\right)^{2}\right.}{\mathrm{n}}}
$$




$$
\begin{aligned}
\operatorname{RMSE}_{\mathrm{Y}} & =\sqrt{\frac{\sum_{\mathrm{i}=1}^{\mathrm{n}}\left(\mathrm{Y}_{\mathrm{si}}-\mathrm{Y}_{\mathrm{ci}}\right)^{2}}{\mathrm{n}}} \\
\mathrm{RMSE}_{\mathrm{Z}} & =\sqrt{\frac{\sum_{\mathrm{i}=1}^{\mathrm{n}}\left(\mathrm{Z}_{\mathrm{si}}-\mathrm{Z}_{\mathrm{ci}}\right)^{2}}{\mathrm{n}}}
\end{aligned}
$$

where:

n: number of CPs.

Xsi, Ysi and Zsi: $X, Y$ and $Z$ coordinates measured with the total station for the ith CP.

Xci, Yci and Zci: X, Y and Z coordinates of the closest cloud's point to (Xsi, Ysi, Zsi).

Interpolation method was inverse distance to square power. An informatic program was developed in Visual Basic V6.0 language for carrying out this task.

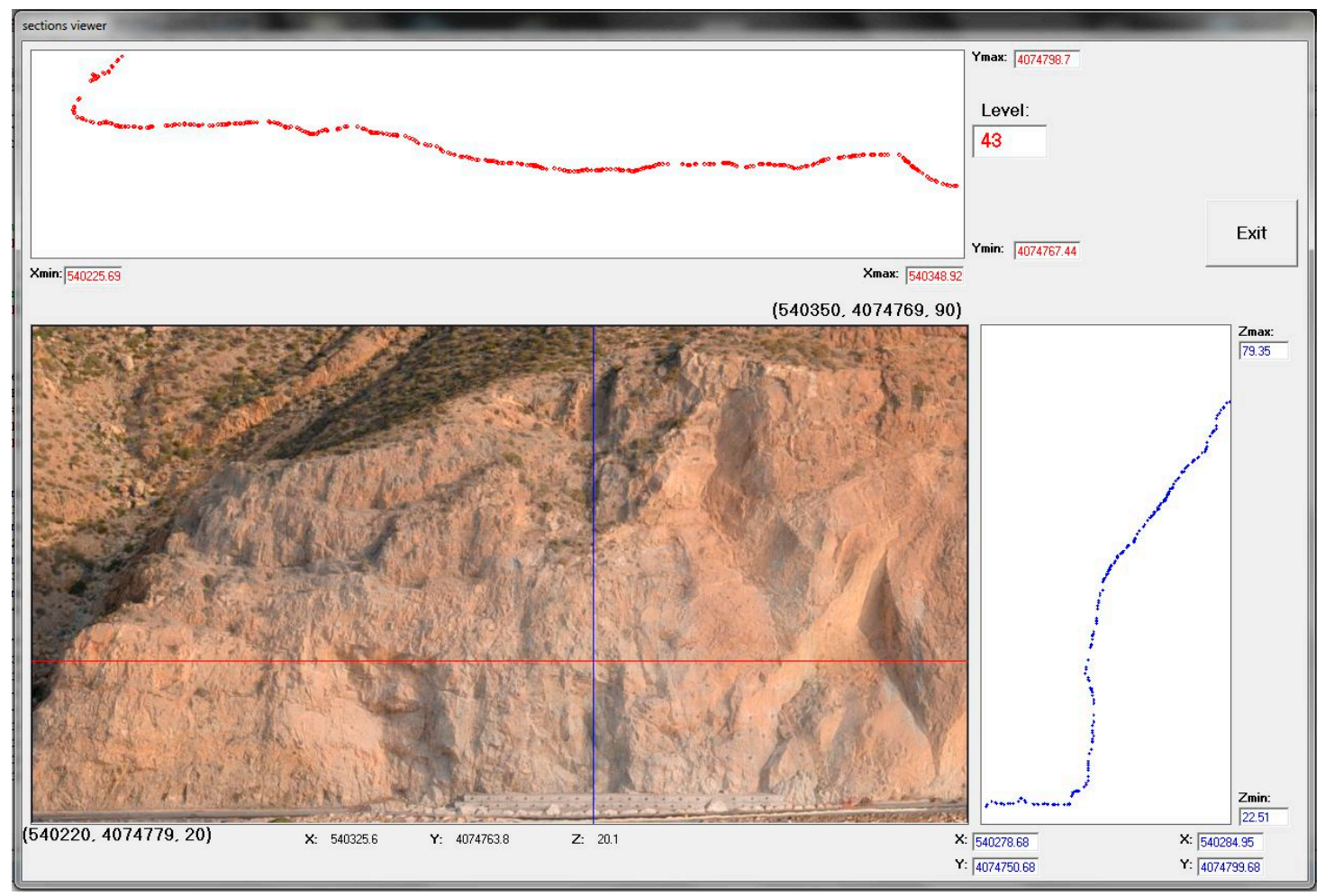

Figure 6. Interface of the informatics program developed to draw contour levels and vertical sections from the point cloud. Red straight line represents the horizontal plane and the blue red line the vertical plane cutting the point cloud. Contour line is represented in the top window by red dots and cross section is represented in the right window by blue dots.

\section{Results and discussion}

Extreme coordinates of the prism containing the raw point cloud were $(540117,4074712,0)$ and (540453, 4074967, 143), which means dimensions of $336 \times 255 \times 143 \mathrm{~m}$ and 11048542 points were generated in the photogrammetric process. As the interest area was smaller than all covered area, this was reduced using the informatics program (Figure $4 \mathrm{a}$ and $4 \mathrm{~b}$ ). The extreme coordinates of the study area were $\left(X_{\min }=540220, Y_{\min }=4074750, Z_{\min }=20\right)$ and $\left(X_{\max }=540350, Y_{\max }=4074800, Z_{\max }=90\right)$, which means dimensions of $130 \times 50 \times 90 \mathrm{~m}$ and the number of point was 2933590 . In this way, all tasks to be carried out on the points cloud will be much faster by having to handle fewest points.

Figure 7 shows a schematic (left) and realistic (right) representation of CPs spatial distribution (red dots), and of the GCPs spatial distribution (blue dots). In this figure the two green dots are points used for orienting points measured with total station.

The fitted plane to the reduced point cloud equation ( $\omega$ in the Figure 7$)$, was

$$
-87.714 \times X-598.373 \times Y+71.319 \times Z+2485619674=0
$$


which was used as projection plane to make the orthophoto. Planes for cross sections were perpendicular to the $A B$ straight line (Figure 7), which is the intersection of $\omega$ with the horizontal plane $\mathrm{Z}=20 \mathrm{~m}$ :

$$
Y=4153968.907+87.714 \times X
$$
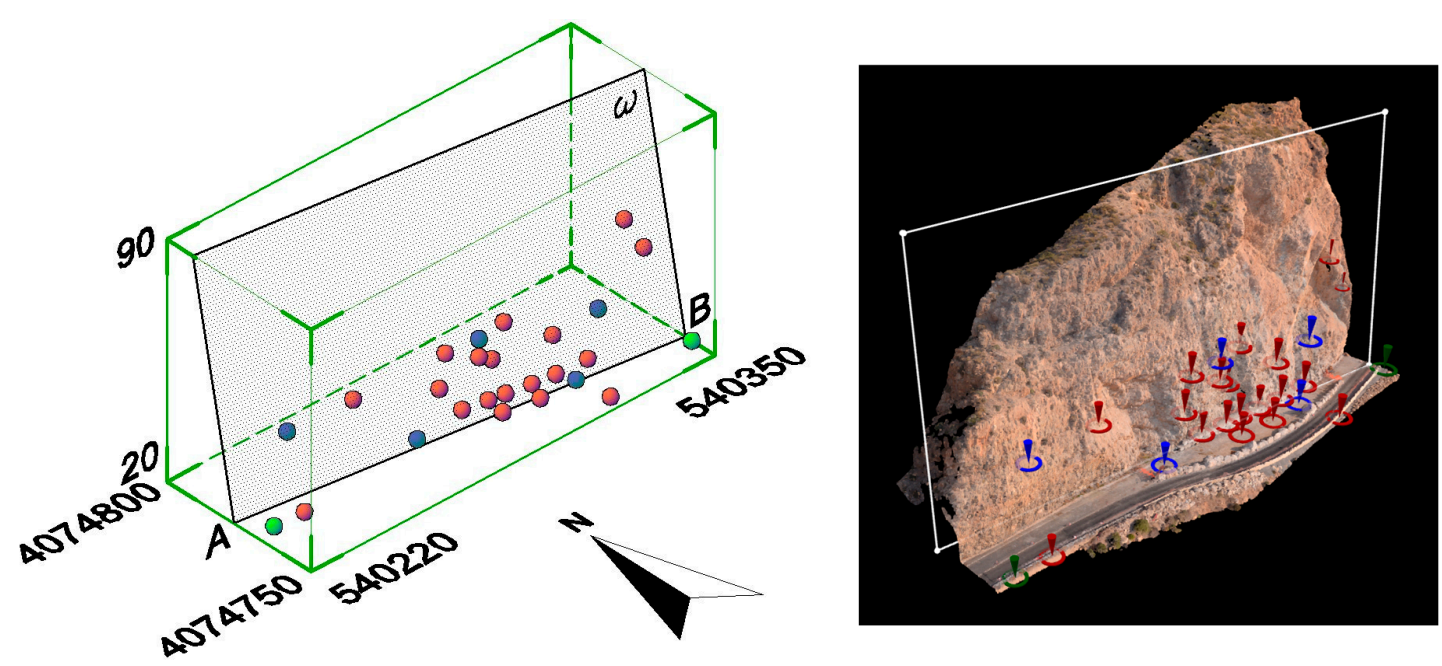

Figure 7. Schematic (left) and realistic (right) representation of the spatial distribution of the measured points as GCPs (blue pots), CPs (red dots), and points for orientating total station measurements (green dots).

Table 1 shows the coordinates of the 18 points measured on the cut slope and the 8 measured on the road $\left(X_{m}, Y_{m}, Z_{m}\right)$. Points 1, 9, 14, 19 and 22 were used as GCPs and the rest were used as CPs. Furthermore, points 23 and 26 were used for orienting the coordinates measured with total station. In the table 1 and Figure 7 can be observed than the maximum altitude of the measured points was $51.677 \mathrm{~m}$. It was not possible to measure points located at higher altitudes doubt to the limitations exposed in the material and methods section. Futhermore, table 1 shows estimated coordinates from points cloud as described in 3.4 section $\left(\mathrm{X}_{\mathrm{e}}, \mathrm{Y}_{\mathrm{e}}, \mathrm{Z} \mathrm{e}\right.$ ), error for each coordinate (Ex, Ex, $\mathrm{Zz}$ ) and RMSE in $\mathrm{X}, \mathrm{Y}$ and $\mathrm{Z}$ directions. Error ranges were from -0.085 to $0.085 \mathrm{~m}(0.170 \mathrm{~m})$ for $\mathrm{X}$ component, from -0.131 to $0.099 \mathrm{~m}(0.230 \mathrm{~m})$ for $Y$ component and from -0.100 to $0.118 \mathrm{~m}(0.218 \mathrm{~m})$ for $Z$ component, indicating similar ranges for each component. RMSE for $X, Y$ and $Z$ directions were $0.053 \mathrm{~m}, 0.070 \mathrm{~m}$ and $0.061 \mathrm{~m}$ respectively which are similar or better to those reported in other works carried out in similar conditions. So, Lucieer et al. [32] used Agisoft PhotoScan Profesional 0.85 software for the 3D terrain reconstruction and reached a geometric accuracy of $0.060 \mathrm{~m}$ in planimetry and $0.044 \mathrm{~m}$ in the $\mathrm{Z}$ component. They worked on an Antartic surface, the flight altitude was $50 \mathrm{~m}$ above ground level and the camera was similar to that used in this work. Turner et al. [44] worked in similar conditions than Lucieer et al. [32] and reported accuracies of 0.100 for planimetric component and 0.150 for Z component. Agüera-Vega et al. [43] used similar UAV-system than that used in this work to study the accuracy of digital surface models and orthophotos derived from unmanned aerial vehicle photogrammetry on terrains with different morphologies and comparing results from different flight altitudes and number of GCPs. At $50 \mathrm{~m}$ flight altitude and 5 GCPs, which are similar conditions to those of our work, they report RMSE values around $0.050 \mathrm{~m}$ for $\mathrm{X}, \mathrm{Y}$ and $\mathrm{Z}$ components. Hugenholtz et al. [45] reported vertical RMSE values of $0.106 \mathrm{~m}$ and $0.097 \mathrm{~m}$ derived from a photogrammetric project on a stockpile, with a rotatory-wing UAV and $100 \mathrm{~m}$ flight altitude, before and after a portion of this pile was removed. In complex-morphology terrains, Carvajal-Ramírez et al. [37] yield planimetric and vertical accuracies of $0.058 \mathrm{~m}$ and $0.100 \mathrm{~m}$ respectively working in a road cut slope. They used a rotatory wing UAV and carried out two flights for the photogrammetry project, one with the cam in vertical position and the second with the camera oriented $45^{\circ}$ with the terrain. 
Table 1. Coordinates of measured points $\left(X_{m}, Y_{m}, Z_{m}\right)$, estimated coordinates $\left(X_{e}, Y_{e}, Z_{e}\right)$, error (Ex, Ey, Zz) and RMSE in X, Y and Z directions. All coordinates are referred to as UTM Zone $30 \mathrm{~N}$ (ETRS89) and the elevation as the mean sea level using the EGM08 geoid model. ${ }^{1}$ points used as GCPs. Rest of points were used as CP. ${ }^{2}$ points used for orienting total station measurements.

\begin{tabular}{|c|c|c|c|c|c|c|c|c|c|}
\hline Id. & $X_{m}$ & $\mathrm{Y}_{\mathrm{m}}$ & $\mathrm{Z}_{\mathrm{m}}$ & $X_{e}$ & $Y_{e}$ & $\mathrm{Z}_{\mathrm{e}}$ & $E_{x}$ & $\mathrm{Ey}_{\mathrm{y}}$ & $\mathrm{E}_{z}$ \\
\hline $1^{1}$ & 540239.580 & 4074779.392 & 35.811 & 540239.580 & 4074779.392 & 35.811 & & & \\
\hline 2 & 540259.982 & 4074778.526 & 35.746 & 540259.997 & 4074778.615 & 35.755 & 0.015 & 0.089 & 0.009 \\
\hline 3 & 540287.114 & 4074769.942 & 24.147 & 540287.179 & 4074769.926 & 24.201 & 0.065 & -0.016 & 0.054 \\
\hline 4 & 540294.329 & 4074768.602 & 24.180 & 540294.302 & 4074768.539 & 24.167 & -0.027 & -0.063 & -0.013 \\
\hline 5 & 540299.056 & 4074767.729 & 24.244 & 540299.089 & 4074767.688 & 24.264 & 0.033 & -0.041 & 0.020 \\
\hline 6 & 540306.281 & 4074766.394 & 24.280 & 540306.289 & 4074766.366 & 24.310 & 0.008 & -0.028 & 0.030 \\
\hline 7 & 540313.089 & 4074765.387 & 24.334 & 540313.106 & 4074765.317 & 24.309 & 0.017 & -0.070 & -0.025 \\
\hline 8 & 540322.771 & 4074764.752 & 24.454 & 540322.849 & 4074764.709 & 24.464 & 0.078 & -0.043 & 0.010 \\
\hline $9^{1}$ & 540329.708 & 4074768.652 & 33.587 & 540329.708 & 4074768.652 & 33.587 & & & \\
\hline 10 & 540315.718 & 4074769.421 & 32.360 & 540315.742 & 4074769.326 & 32.341 & 0.024 & -0.095 & -0.019 \\
\hline 11 & 540298.763 & 4074772.219 & 32.008 & 540298.732 & 4074772.088 & 31.952 & -0.031 & -0.131 & -0.056 \\
\hline 12 & 540281.862 & 4074772.198 & 31.625 & 540281.849 & 4074772.243 & 31.714 & -0.013 & 0.045 & 0.089 \\
\hline 13 & 540284.104 & 4074772.528 & 40.590 & 540284.036 & 4074772.482 & 40.607 & -0.068 & -0.046 & 0.017 \\
\hline $14^{1}$ & 540293.545 & 4074771.006 & 40.984 & 540293.545 & 4074771.006 & 40.984 & & & \\
\hline 15 & 540293.420 & 4074770.882 & 35.962 & 540293.393 & 4074770.773 & 35.989 & -0.027 & -0.109 & 0.027 \\
\hline 16 & 540302.084 & 4074771.639 & 41.437 & 540302.043 & 4074771.542 & 41.501 & -0.041 & -0.097 & 0.064 \\
\hline 17 & 540345.107 & 4074769.425 & 43.532 & 540345.058 & 4074769.462 & 43.507 & -0.049 & 0.037 & -0.025 \\
\hline 18 & 540341.672 & 4074772.535 & 51.677 & 540341.626 & 4074772.459 & 51.582 & -0.046 & -0.076 & -0.095 \\
\hline $19^{1}$ & 540272.788 & 4074770.053 & 22.426 & 540272.788 & 4074770.053 & 22.426 & & & \\
\hline 20 & 540294.803 & 4074764.157 & 22.753 & 540294.881 & 4074764.202 & 22.653 & 0.078 & 0.045 & -0.100 \\
\hline 21 & 540305.133 & 4074762.180 & 22.874 & 540305.068 & 4074762.217 & 22.787 & -0.065 & 0.037 & -0.087 \\
\hline $22^{1}$ & 540316.384 & 4074761.928 & 22.914 & 540316.384 & 4074761.928 & 22.914 & & & \\
\hline $23^{2}$ & 540346.656 & 4074754.387 & 23.533 & 540346.606 & 4074754.327 & 23.465 & -0.050 & -0.060 & -0.068 \\
\hline 24 & 540317.141 & 4074750.767 & 23.444 & 540317.160 & 4074750.866 & 23.562 & 0.019 & 0.099 & 0.118 \\
\hline 25 & 540234.241 & 4074767.622 & 21.255 & 540234.156 & 4074767.685 & 21.205 & -0.085 & 0.063 & -0.050 \\
\hline \multirow[t]{2}{*}{$26^{2}$} & 540225.189 & 4074768.419 & 21.047 & 540225.274 & 4074768.451 & 21.139 & 0.085 & 0.032 & 0.092 \\
\hline & & & & & & RMSE & 0.053 & 0.070 & 0.061 \\
\hline
\end{tabular}

As regard the orthophoto, figure 8 shows the orthophoto obtained using a horizontal plane (a) and that obtained using the fitted plane (b). As the surface under study was the cut slope, orthophoto projected on a traditional horizontal plane shows less information than that projected on the plane used in this work because this offers the optimal vision to detect, describe and to measure cracks, location of rocks with danger of falling into the road, take measurements or get information to plan works on the cut slope. Furthermore, in the orthophoto of figure 8a terrain located at the top of the cut slope hidden to another located at the bottom. This can be observed around the center of the picture. Nevertheless, orthophoto of figure $8 \mathrm{~b}$ shows with much more detail than figure $8 \mathrm{a}$ the area under study. 

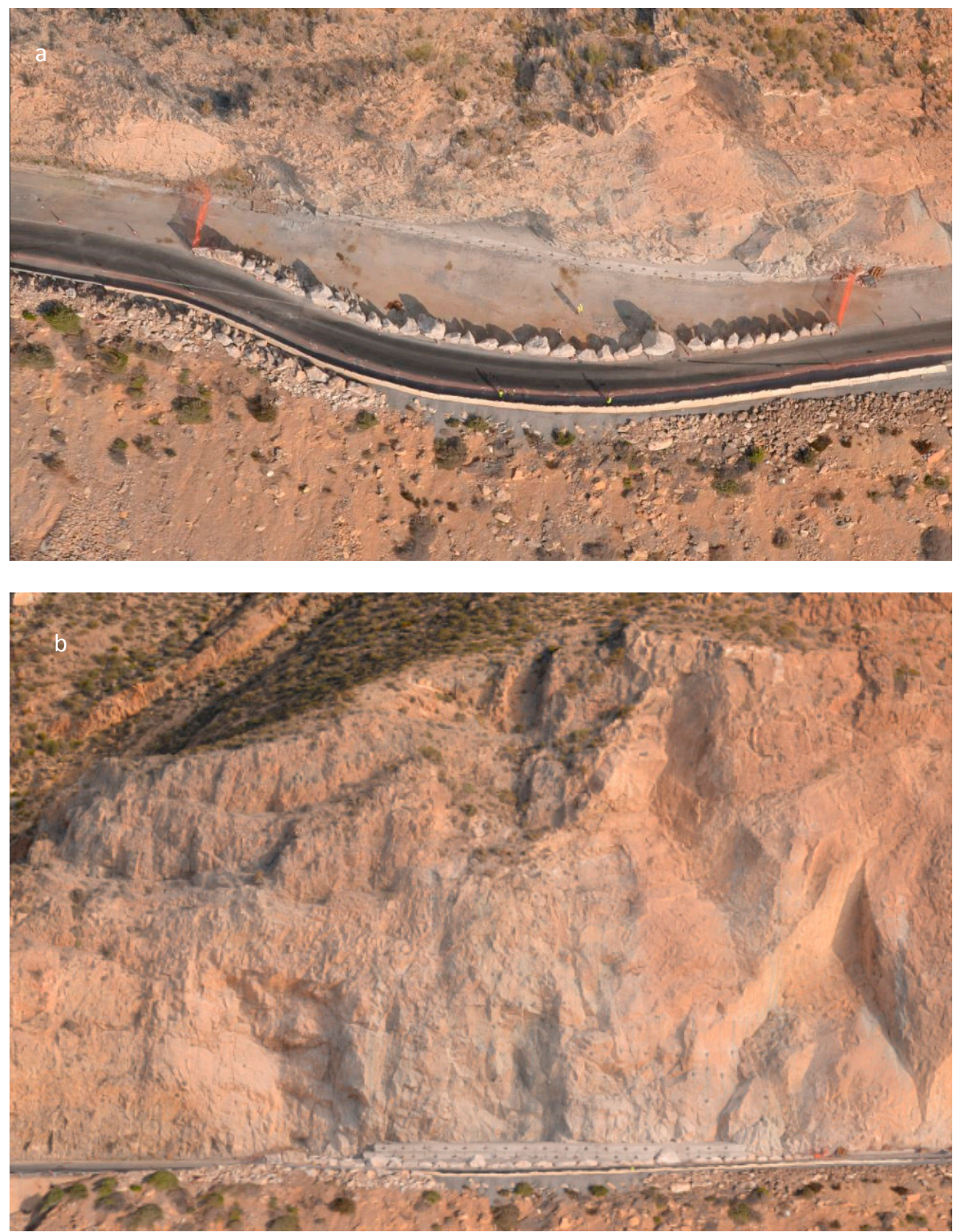

Figure 8. Orthophoto obtained using a horizontal plane (a) and that obtained using the fitted plane (b).

In addition, contour lines and cross sections yielded from the dense point cloud give valuable information to the engineers, geologists and other technicians for proposing the necessary works on the cut slope to repair it and avoid a new landslide. For this terrain, if a horizontal plane of projection is used, the DSM would not have represented the reality since for a given coordinates $X, Y$, a single value of $Z$ coordinate would be given by the DSM, but this is not the case for certain zones of the studied terrain. The developed informatics program has made possible to obtain contour lines directly from point cloud, so these represent the terrain truthfully.

As stated in section 3.3, a critical adjustment of this program was to fix the cutting planes width for generating contour lines and cross sections. Extraction of intersection points between point cloud and cutting plane was carried out taking into account $0.5 \mathrm{~cm}, 1 \mathrm{~cm}, 2 \mathrm{~cm}$ and $5 \mathrm{~cm}$ plane widths and studying by comparison results using the developed informatics program. Figure 9 shows the results for three cross sections (CS1, CS2 and CS3). The number in the bottom of each section is the number of point extracted from the point cloud. When $0.5 \mathrm{~cm}$ width is fixed, observed accuracy of 
cross section representation is not enough because exist quite gaps between extracted points. When 5 $\mathrm{cm}$ width is fixed, appear representation sections with an elevate number of extracted points which make confuse the section. Nevertheless, differences between sections representation taking into account $1 \mathrm{~cm}$ and $2 \mathrm{~cm}$ width were not remarkable, both values yield well defined representation sections. Finally, for our study, $1 \mathrm{~cm}$ width was fixed to generate the contour lines and cross sections.

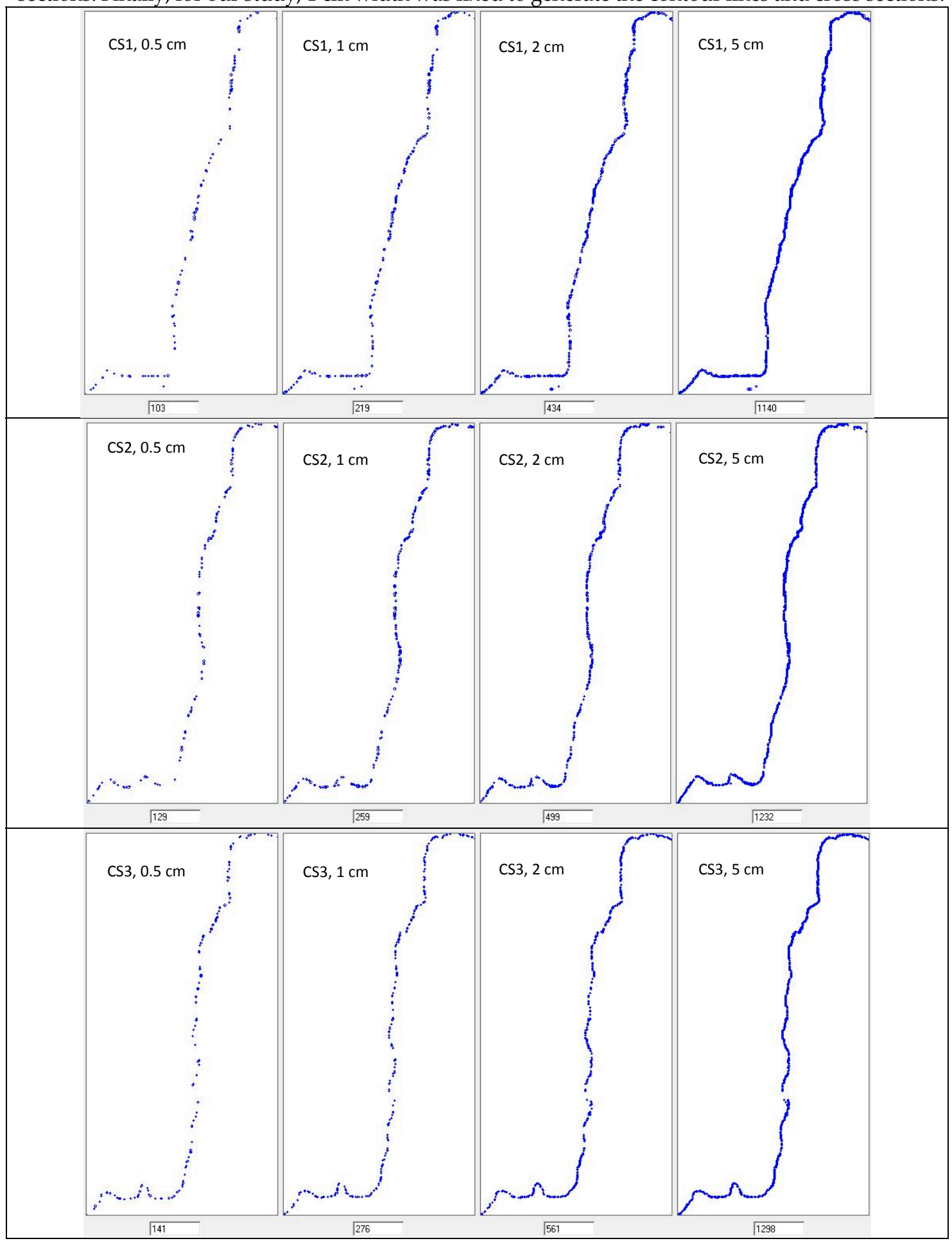

Figure 9. Example of three cross sections (CS1, CS2 and CS3) obtained with the informatics program developed, taking into account a cutting plane width of $0.5 \mathrm{~cm}, 1 \mathrm{~cm}, 2 \mathrm{~cm}$ and $5 \mathrm{~cm}$. 
Figure 10 shows the contour levels yielded from DSM (a), and from point cloud (b). In the first case, no contour line crosses another one, but in the second case it can be observed than several contour lines cross other lines.

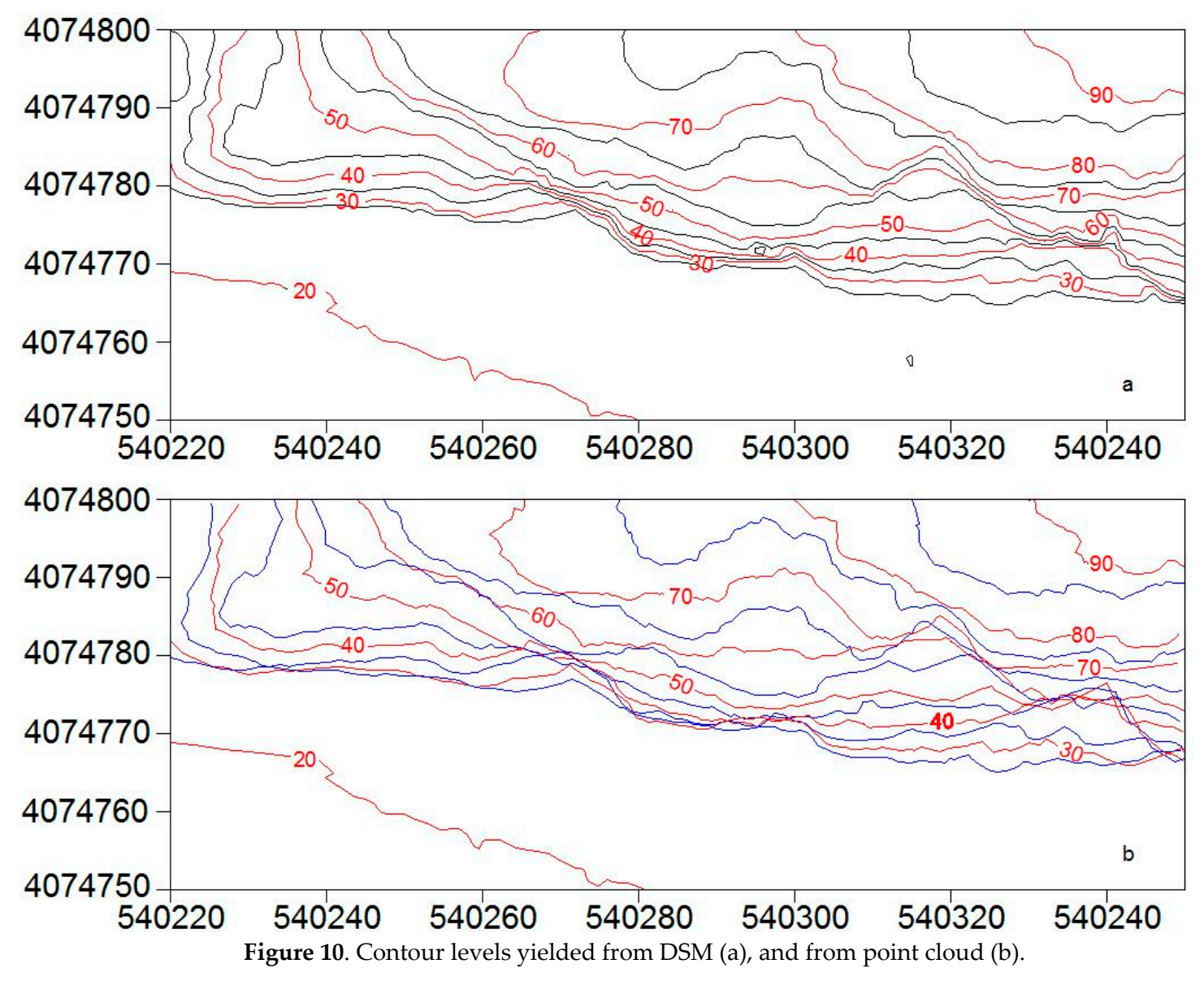

Similary, the developed program generates the cross sections from point cloud yielded in the photogrammetry project. Figure 11 shows several cross sections in which it can be observed that for a given planimetric point $X, Y$, there may be more than one value of $Z$ because the terrain morphology which can be represented if these sections are generated from point cloud (blue lines in figure 11), but no if these are generated from a DSM (red lines in figure 11).

\section{Conclusions}

The use of UAVs as platforms that can be coupled with different types of sensors to capture information at very high geometric and temporal resolution is being implemented from several years ago. This paper proposes a methodology for reconstruct extreme topography that has been developed in order to obtain useful information for engineers, geologists and other technicians which are interested in the study of this type of these surfaces. The equipment used in this study, composed of a light UAV and a non-metric camera has been shown as the only system capable of achieving that goal since for extreme topography, terrestrial instruments as global navigation satellite system (GNSS), terrestrial laser scanner and aerial or space surveys are no suitable. In this case, terrestrial instruments are useful for the measurement of GCPs and CPs.

The use of SfM tecniques, incorporated in moderns UAV-photogrammetry commercial software, allows us to obtain a dense point cloud representing the studied surface from which, Digital Surfaces Models and orthophotos can be derived. Point density has been enough to represent 


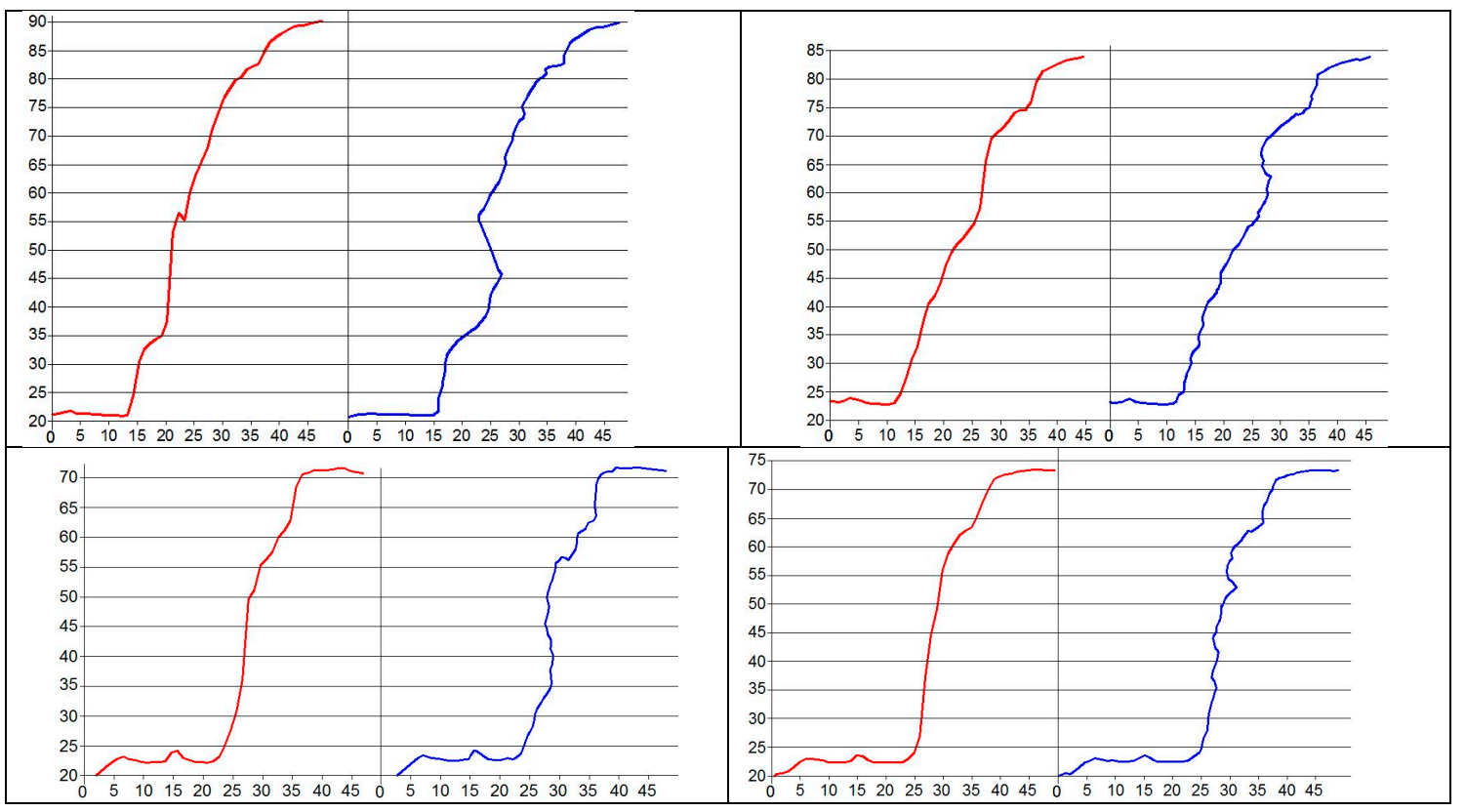

Figure 11. Example of four cross sections generated from DSM (red lines) and from point cloud (blue lines).

accurately the terrain. So, RMSEs found in X, Y and Z direction have been $0.053 \mathrm{~m}, 0.070 \mathrm{~m}$ and 0.061 $\mathrm{m}$, respectively, similar to the best accuracies reported in other works for similar conditions.

Traditionally in topography, the reference plane to project the orthophoto has been horizontal but there are times when it is necessary to project on a non-horizontal plane, such as surfaces with a very high slope. In this sense, the methodology proposed in this work, consisting of projecting on the plane that best fits the surface under study, has been shown as an adequate alternative since the derived orthophoto allows to carry out different types of studies.

In addition, DSM may not reliably represent surface geometry and is necessary to work with cloud point to generate useful information. For this purpose, the developed software in this work has proved suitable to generate manageable information, as contour levels and cross sections, useful for the elaboration, for example, of projects for repairing or maintenance works of cut slopes with extreme topography. Figure 12 shows the cut slope aspect after the initial works projected using the information derived from the methodology described in this study. Point density derived from UAV-photogrammetry has allowed us to represent the terrain from contour lines and cross sections, which is the used format to elaborate the plans to carry out works on terrains. For each cutting plane that generates a contour line or cross section, it has been sufficient to consider one centimeter width to obtain accuracy representation of these lines.

\section{Acknowledgments.}

This work was supported by grant G-GI3000/IDIW, from Junta de Andalucía (Spain), co-financed with FEDER funds of the European Union.

\section{Author Contributions.}

Francisco Agüera-Vega, Fernando Carvajal-Ramírez and Patricio J. Martínez-Carricondo conceived, designed and performed the experiments. Patricio J. Martínez-Carricondo and Julian Sánchez-Hermosilla performed the photogrammetric project; Francisco Agüera-Vega and Fernando Carvajal-Ramírez developed the informatics programs. All authors analyzed and interpreted the data and results. Francisco Agüera-Vega wrote the paper with contributions from the other authors. 


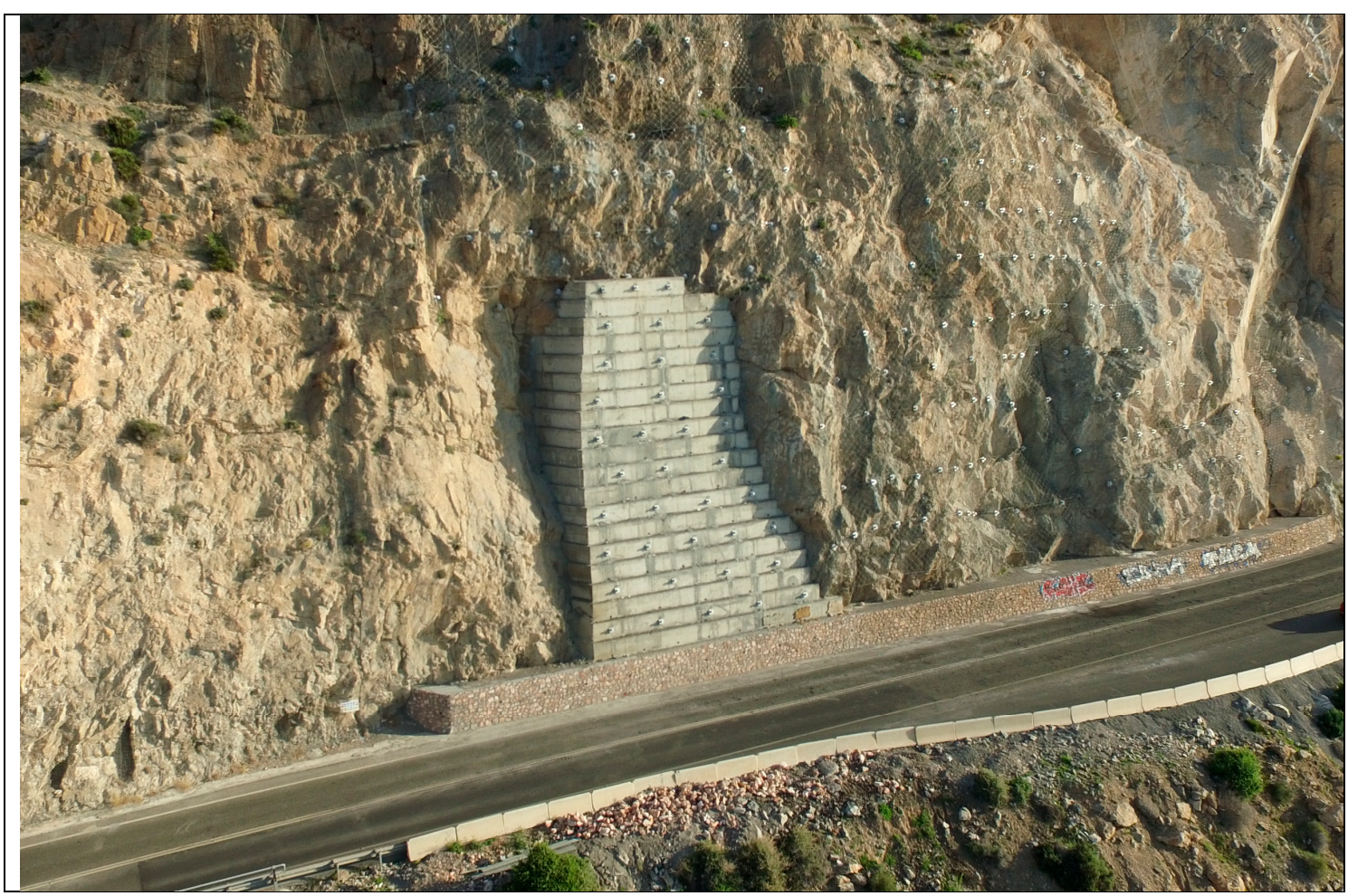

Figure 12. Cut slope aspect after the initial works projected using the information derived from the methodology described in this study.

\section{References}

1. Fuller, I., Large; A., Charlton, M.; Heritage, G.; Milan, D. Reach-scale sediment transfers: an evaluation of two morphological budgeting approaches. Earth Surface Processes and Landforms 2003, 28 (8), 889-903.

2. Brasington, J.; Rumsby, B.T.; McVey, R.A. Monitoring and modelling morphological change in braided river systems using the Global Positioning System. Earth Surf. Processes Landforms 2000, 25, 973-990. DOI: 10.1002/1096-9837(200008)25:9<973::AID-ESP111>3.0.CO;2-Y

3. Javernick, L.; Brasington, J.; Caruso, B. Modeling the topography of shallow braided rivers using Structure-from-Motion photogrammetry. Geomorphology 2014, 213, 166-182. http://dx.doi.org/10.1016/j.geomorph.2014.01.006

4. Brasington, J.; Vericat, D.; Rychkov, I. Modeling river bed morphology, roughness, and surface sedimentology using high resolution terrestrial laser scanning. Water Resources Research 2012, 48. DOI: 10.1029/2012WR012223.

5. Notebaert, W.; Houtman, F.; Opstal, F. V.; Gevers, W.; Fias, W.; Verguts T. Post-error slowing: An orienting account. Cognition 2009, 111(2), 275-279.

6. Lane, S.N. The measurement of River channel morphology using digital photogrammetry. The Photogrammetric Record 2000, 16(96), 937-961. DOI: 10.1111/0031-868X.00159.

7. Shears, J.C.; Allan, J.W. Softcopy photogrammetry and its uses in GIS. International Archives of Photogrammetry and Remote Sensing 1996, XXXI, part B4, Vienna, Austria.http://www.isprs.org/proceedings/XXXI/congress/part4/70_XXXI-part4.pdf ～(accessed on 30/3/2017).

8. Hilldale, R.C.; Raff, D. Assessing the ability of airborne LiDAR to map river bathymetry. Earth Surface Process and Landforms 2008, 33(5), 773-783. DOI: 10.1002/esp.1575.

9. Nex, F.; Remondino, F. UAV for 3D mapping applications: a review. Applied Geomatics 2014, 6, 1-15. DOI: $10.1007 / \mathrm{s} 12518-013-0120-\mathrm{x}$.

10. Clapuyt, F.; Vanacker, V.; Van Oost, K. Reproducibility of UAV-based earth topography reconstructions based on Structure-from-Motion algorithms, Geomorphology 2016, 260, 4-15. DOI: 10.1016/j.geomorph.2015.05.011 
11. Laliberte, A.S.; Herrick, J.E.; Rango, A; Winters, C. Acquisition, Orthorectification, and Object-based Classification of Unmanned Aerial Vehicle (UAV) Imager y for Rangeland Monitoring. Photogrammetric Engineering \& Remote Sensing 2010, $76 \quad$ (6), https://www.ars.usda.gov/ARSUserFiles/30501000/acquisition.pdf.

12. Harwin, S.; Lucieer; A. Assesing the accuracy of georeferenced point clouds produced via multi-view stereopsis from unmanned aerial vehicle (UAV) imagery, Remote Sensing 2012 4, 1573-1599. doi:10.3390/rs4061573

13. Hugenholtz, C.H.; Whitehead, K.; Brown, O.W; Barchyn, T.E.; Moorman, B.J.; LeClair, A.; Riddell, K.; Hamilton, T. Geomorphological mapping with a small unmanned aircraft system (sUAS): Feature detection and accuracy assessment of a photogrammetrically-derived digital terrain model. Geomorphology 2013, 194, 16-24. . http://dx.doi.org/10.1016/j.geomorph.2013.03.023.

14. Aber, J.S.; Marzolff, I.; Ries, J.B. Small-format aerial photography. Principles, techniques and geoscience applications 2010, Elsevier, Amsterdam.

15. Immerzeel, W.W.; Kraaijenbrink, P.D.A.; Shea, J.M.; Shrestha, A.B.; Pellicciotti, F.; Bierkens, M.F.P.; de Jong, S.M. High-resolution monitoring of Himalayan glacier dynamics using unmanned aerial vehicles 2014. Remote Sensing of Environment, 150, 93-103. http://dx.doi.org/10.1016/j.rse.2014.04.025.

16. Lambers, K.; Eisenbeiss, H.; Sauerbier, M.; Kupferschmidt, D.; Gaisecker, T.; Sotoodeh, S; Hanusch. T. Combining photogrammetry and laser scanning for the recording and modelling of the Late Intermediate Period site of Pinchango Alto, Palpa, Peru. Journal of Archaeological Science 2007,34, 1702-1712. http://dx.doi.org/10.1016/j.jas.2006.12.008.

17. Colomina, I.; Molina, P. Unmanned aerial systems for photogrammetry and remote sensing: a review. ISPRS Journal of Photogrammetry and Remote Sensing 2014, 92, $79-97$. http://dx.doi.org/10.1016/j.isprsjprs.2014.02.013

18. Liu, P.; Chen, A.Y.; Yin-Nan, H.; Jen-YU, H.; Jihn-Sung, L.; SHIL-Chung, K.; Tzong-Hann, W.; Ming-Chang, W.; Meng-Han; T. A review of rotorcraft unmanned aerial vehicle (UAV) developments and applications in civil engineering. Smart Structures and Systems 2014, 13 (6), 1065-1094.

19. Atkinson. K.; Close range photogrammetry and machine vision, Whittles Publishing. Caithness. 1996

20. Hartley, R.; Zisserman, A. Multiple view geometry in computer vision, Cambridge University Press, 2003 NewYork.

21. Snavely, N.; Seitz, S.M.; Szeliski,R. Modelling the world from internet photo collections. International Journal of Computer Vision 2008, 80, 189-210. DOI: 10.1007/s11263-007-0107-3.

22. Westoby, M.J.; Brasington, J.; Glasser, N.F.; Hambrey, M.J.; Reynolds, J.M. Structure from Motion photogrammetry: A low cost, effective tool for geoscience applications. Geomorphology 2012, 179, 300314. http://dx.doi.org/10.1016/j.geomorph.2012.08.021.

23. Vasuki, Y.; Holden, E.J.; Kovesi, P.; Micklethwaite, S. Semi-automatic mapping of geological structures using UAV-based photogrammetric data: an image analysis approach. Computers \& Geosciences 2014, 69, 22-32. http://dx.doi.org/10.1016/j.cageo.2014.04.012.

24. Furukawa, Y.; Ponce, J. Accurate, dense, and robust multi-view stereopsis. In Proceedings of the 2007 IEEE Conference on Computer Vision and Pattern Recognition, Minneapolis, MN, USA, 18-23 June 2007 (1), 1-8.

25. Lowe, D.G. Distinctive image features from scale-invariant keypoints. Int. J. Comput. Vis. 2004, 60, 91-110. DOI: 10.1023/B:VISI.0000029664.99615.94.

26. Lowe, D.G. Object recognition from local scale-invariant features. Proc. 7th International Conference on Computer Vision (ICCV'99) (Corfu, Greece): 1150-1157. doi:10.1109/ICCV.1999.790410.

27. Remondino, F.; El-Hakim, S. Image-based 3d modelling: A review. Photogramm. Rec.2006, 21, $269-291$.

28. Juan, L.; Gwun, O. A comparasion of SIFT, PCA-SIFT and SURF. Int. J. Image Process 2009, 3, 143-152.

29. Fonstand, M.A.; Dietrich, J.T.; Courvill, B.C.; Jensen, J.L.; Carbonneau, P.E. Topographic structure from motion: a new development in photogrammetric measurement. Earth Surface Process and Landforms 2013, 38 (4), 421-430. DOI: 10.1002/esp.3366.

30. Lucieer, A.; Turner, D.; King, D.H.; Robinson, S.A. Using an unmanned aerial vehicle (UAV) to capture micro-topography of Antarctic moss beds. International Journal of Applied Earth Observation 2013, 27 (part A), 53-62. http://dx.doi.org/10.1016/j.jag.2013.05.011.

31. Mancini, F.; Dubbini, M.; Gattelli, M.; Stecchi, F.; Fabbri, S.; Gabbianelli, G. Using Unmanned Aerial Vehicles (UAV) for High-Resolution Reconstruction of Topography: The Structure from Motion Approach on Coastal Environments. Remote Sensing 2013, 5, 6880-6898. doi:10.3390/rs5126880. 
32. Lucieer, A.; de Jong, S.M.; Turner, D. Mapping landslide displacements using Structure from Motion (SfM) and image correlation of multi-temporal UAV photography. http://journals.sagepub.com/doi/full/10.1177/0309133313515293

33. Tonkin, T.N.; Midgley, N.G.; Graham, D.J.; Labadz, J.C. The potential of small unmanned aircraft systems and structurefrom-motion for topographic surveys: A test of emerging integrated approaches at Cwm Idwal, North Wales. Geomorphology 2014, 226, 35-43. http://dx.doi.org/10.1016/j.geomorph.2014.07.021.

34. Eltner, A.; Baumgart, P.; Maas, H.; Faust, D. Multi-temporal data for automatic measurement of rill and interrill erosion on losses soil. Earth Surface Processes and Landforms, 2014, 40(6), 741-755.

35. Agüera-Vega, F.; Carvajal-Ramírez, F; Martínez-Carricondo, P.J. Accuraccy of Digital surface Models and Orthophotos Derived from Unmanned Aerial Vehicle Photogrammetry. Journal of Surveying Engineering 2016, 04016025-1, 04016025-10. DOI: http://dx.doi.org/10.1061/(ASCE)SU.1943-5428.0000206.

36. Fernández, T.; Pérez, J.L.; Cardenal, J.; Gómez, J.M.; Colomo, C.; Delgado, J. Analysis of Landslide Evolution Affecting Olive Groves Using UAV and Photogrammetric Techniques. Remote Sensing 2016, 8(10), 837; doi:10.3390/rs8100837.

37. Carvajal-Ramirez, F.; Agüera-Vega, F.; Martínez-Carricondo, P.J. Effects of image orientation and ground control points distribution on unmanned aerial vehicle photogrammetry projects on a road cut slope. Journal of Appl. Remote Sens. 2016, 10(3), 034004. doi: 10.1117/1.JRS.10.034004.

38. http://wiki.mikrokopter.de/MikroKopterTool. (accessed on 30/3/2017).

39. https://pix4d.com/product/pix4dmapper-pro/. (accessed on 30/3/2017).

40. Verhoeven, G.J. Taking computer vision aloft - archaeological three-dimensional reconstructions from aerial photographs with Photoscan. Archaeological Prospection 2011, 18, 67-73. DOI: 10.1002/arp.399

41. Rosnell, T.; Honkavaara, E. Point cloud generation from aerial image data acquired by a quadracopter type micro unmanned aerial vehicle and a digital still camera. Sensors 2012, 12(1), 453-480. doi:10.3390/s120100453.

42. Tahar, K.N. An evaluation on different number of ground control points in unmanned aerial vehicle photogrammetric block. International Archives of the Photogrammetry, Remote Sensing and Spatial Information Sciences 2013, Vol. XL-2/W2, ISPRS. 8 ${ }^{\text {th }}$ 3DGeoInfo Conference \& WG II/2 Workshop, Istanbul, Turkey. http://www.int-arch-photogramm-remote-sens-spatial-inf-sci.net/XL-2-W2/93/2013/.

43. Agüera-Vega, F.; Carvajal-Ramírez, F; Martínez-Carricondo, P.J. Assessment of photogrammetric mapping accuracy based on variation ground control points number using unmanned aerial vehicle. Measuremen 2017, 98, 221-227. http://dx.doi.org/10.1016/j.measurement.2016.12.002.

44. Turner, D.; Lucieer, A.; Watson, C. An automated technique for generating georectified mosaics from ultra-high resolution unmanned aerial vehicle (UAV) imagery, based on structure from motion (SfM) point clouds. Remote Sensing 2012, 4(5), 1392-1410. doi:10.3390/rs4051392.

45. Hugenholtz, C.H.; Walker, J.; Brown, O.; and Myshak, S. Earthwork volumetrics with an unmanned aerial vehicle and Softcopy Photogrammetry. Journal Surveying Engineering 2015, 141(1), 06014003-106014003-5. DOI: http://dx.doi.org/10.1061/(ASCE)SU.1943-5428.0000138.

(C) 2017 by the authors. Licensee Preprints, Basel, Switzerland. This article is an open access article distributed under the terms and conditions of the Creative Commons by Attribution (CC-BY) license (http://creativecommons.org/licenses/by/4.0/). 